\title{
LOS FUNDAMENTOS SOCIALES DEL TERCER SECTOR
}

\author{
ISABEL DE LA TORRE
}

Universidad Autónoma de Madrid

\section{PALABRAS CLAVE ADICIONALES}

Hecho social total, Intercambio plural, Bienes relacionales, Redes de acción social, Confianza generalizada, Sociedad civil organizada.

\author{
ADDITIONAL KEYWORDS \\ Total Social Fact, Plural Interchange, Relational \\ Goods, Networks of Social Action, Generalised \\ Trust, Organized Civil Society.
}

RESUMEN. La teoria del don, y las posibilidades explicativas que brindan su acepción conceptual y su aplicación metodológica, es el punto de partida para analizar los comportamientos prosociales, presentes en las entidades que integran el Tercer Sector: asociaciones, fundaciones, mutualidades, cooperativas y sociedades laborales. En todas estas entidades se ejercita un intercambio de bienes y servicios, que no pueden ser explicados ni por las reglas del mercado ni por los principios de redistribución del Estado. Los principios de altruismo, solidaridad y ayuda mutua, que inspiran los comportamientos prosociales, suelen practicarse a través de las redes de solidaridad organizada y favorecen el desarrollo de la sociedad civil.

ABSTRACT. The theory of the gift, and the explanatory possibilities that its conceptual meaning offer and its methodological application, is the starting point to analyse the pro-social behaviours, present in the organizations that integrate the Third Sector: associations, foundations, benefit societies, co-operatives and labour societies. In all of these organizations, an interchange of goods and services is exercised, that can not be explained neither by the rules of the market nor by the principles of redistribution of the state. Altruism, solidarity and mutual principles, that inspire the pro-social behaviours, are usually practice through the networks of organized solidarity, that are based on the generalised trust and favour the civil society.

- Agradezco a M. Beltrán sus comentarios y A.D. Gallego sus aportaciones.

E-mail: Isabel.torre@uam.es

Revista Internacional de Sociología (RIS)

Tercera Época, n 35, Mayo-Agosto, 2003, pp. 105-125. 
R I S

REVISTA INTERNACIONAL DE SOCIOLOCIIA

№ 35, Mayo-Agosto, 2003

ISABEL DE LA TORRE

El término Tercer Sector fue formulado hace treinta años para designar los espacios de actuación pública que no son atribuibles a la administración ni al funcionamiento de los intereses privados en el mercado (Levitt, 1973). Desde entonces ha experimentado un uso creciente, compartido con otros términos alternativos como Sector No Lucrativo, Economía Social y Organizaciones Voluntarias, para designar el conjunto de entidades que, sin pertenecer a la esfera pública ni al sector privado lucrativo, realizan actividades que proporcionan bienes y servicios a la sociedad y que, en los últimos años, por el número de publicaciones y por las investigaciones en curso (Barea y Monzón, 2002; Pérez Díaz, 2003; Rodríguez Cabrero, 2003), ha consolidado su protagonismo.

El objetivo de estas reflexiones es ofrecer una explicación teórica que contribuya a confirmar la naturaleza social del Tercer Sector, que en su acepción más amplia está constituido por las asociaciones y las fundaciones, integradas habitualmente en el Sector No Lucrativo, y por las mutualidades, las cooperativas y las sociedades laborales, que se adscriben a la Economía Social.

\section{EL CONCEPTO DE DONACIÓN Y LA TEORÍA DEL DON}

Una de las teorías que muestran un mayor vigor explicativo con relación a la naturaleza de los comportamientos sociales identificados con el Tercer Sector es la que utiliza el concepto de donación en el marco de la teoría del don y su espíritu, siguiendo el pensamiento de Marcel Mauss, quien en su "Ensayo sobre los dones"1 lo considera como un fenómeno social total, al impregnar todas las esferas de la vida social.

El Potlatch - tipo de intercambio que estudió Mauss - es una institución de intercambio recíproco que se ejercitaba entre los individuos según el rango social. El mecanismo por el que se guiaba era muy simple, ya que aquella persona que recibía un regalo en el sistema del Potlatch, debía devolverlo en su momento con creces. Esta forma de dar y recibir de forma continua y precisa es lo que hace que este tipo de intercambio sea considerado como un hecho social total, pues los dones que se intercambian refieren a un sistema simbólico complejo que afecta a todos los ámbitos de la vida social. Este intercambio, a diferencia del que se establece en el mercado, no es aislado y no se hace de una sola vez, sino que continuamente se encuentra en movimiento; es difícil saber quién es el donante y quién el donatario, y cuál es la fase del proceso de intercambio en la

\footnotetext{
' Maus (1991) analizó las formas de intercambio en las tribus del noroeste americano, que se identifican con la costumbre del Potlach y que genera tres obligaciones: dar, recibir y restituir.
} 
que se encuentran. Detrás del intercambio recíproco de dones existe una espiral de vínculos que configuran y dan forma a la posición social de las distintas tribus.

La finalidad de estos intercambios es la búsqueda del honor, del prestigio y de la autoridad. Son importantes los bienes que una tribu tenga, pero son los bienes que da los que le confieren prestigio y riqueza, y cuanto más dé, más admiración obtendrá y más prestigio y autoridad acumulará su jefe. Aquél que acepta la donación asume que el otro tiene más autoridad, y sabe que en un determinado periodo de tiempo debe devolver lo recibido; si no es así, perderá toda autoridad, y si lo hace dando objetos de más valor, le arrebatará al primero la autoridad.

Muchos de los bienes que se intercambian están ligados a la persona, es decir, tienen su espíritu dentro, y esto es lo que les da valor para ser devueltos. ¿Cómo definir este tipo de valor?. Para explicar la circulación de este "espíritu" como la esencia del valor del intercambio, el antropólogo Elsdon Best, en 1909, recoge la disertación del sabio maorí Tamati Ranapiri².

El don que impregna el Potlatch tiene dos momentos que se dan en toda relación y un tercero que sólo se da en este tipo de intercambios, lo que hace que sea un hecho social total (Rodríguez, 1984). El primer momento es la obligación de dar, acto que demuestra riqueza y que los dioses están con ese jefe y le dan autoridad, ya que la donación es entendida como "poner a la sombra de su nombre a terceros". En segundo lugar, se encuentra la obligación de aceptar la donación, ya que, si no se hace, se confiesa la inferioridad, y si se acepta, es porque existe la certeza de que se podrá devolver. En último lugar, se encuentra la restitución o la devolución del don, que debe ser similar o superior al recibido, pues si no, se puede perder la condición de hombre libre, mostrando de este modo que el don es símbolo de superioridad, pues aceptar sin devolver es símbolo de inferioridad. Desde esta perspectiva el don puede ser considerado como una forma de intercambio recíproco dentro de un sistema de comunicación que posiciona a los grupos y refuerza la cohesión social.

Las formas de reciprocidad han sido descritas por autores como Polanyi (1989) como una de las tres formas posibles de intercambio - mercado, redistribución y reciprocidad - que pueden darse en la sociedad. Son opuestas al mercado, pues

\footnotetext{
${ }^{2}$ El texto aparece recogido en Ibáñez (1994) que, a su vez, cita el texto de E. Best "Maori Forest Lore" Part. III, en Transaction of the New Zealand Institute, 1909. "Y ahora , a propósito del hau del bosque. Este hau no es el hau que sopla. No. Te lo voy a explicar cuidadosamente. Tú tienes un objeto de valor que me das. No tenemos ningún acuerdo en cuanto al pago. Y resulta que yo le doy ese objeto a algún otro, y el tiempo pasa y pasa, y ese hombre piensa que posee ese objeto de valor y que debe devolverme en pago cualquier cosa, y así lo hace. Pero ese objeto de valor que me es dado es el hau del objeto de valor que me había sido dado por ti. Es preciso que te lo dé. No sería justo que yo lo guarde para mí. Porque ese objeto es el hau del otro objeto de valor...Eso es el hau, el hau de los objetos de valor, el hau del bosque, y basta por hoy".
} 
RIS

REVISTA INTERNACIONAL DE SOCIOLOCIA

no se basan en un intercambio de equivalentes a partir de una base monetaria, con la que toda prestación y todo bien son susceptibles de ser comprados y vendidos y tampoco buscan maximizar el beneficio con el intercambio. También se diferencian del principio de redistribución, que se atribuye al Estado al concentrar y distribuir los recursos según las necesidades de la sociedad, estableciendo un orden de prioridad. La reciprocidad se define como una forma de intercambio de no equivalentes que, o bien responde al principio universal de solidaridad, o bien se explica desde la práctica del establecimiento y fortalecimiento de lazos sociales a través del intercambio de regalos. El concepto de reciprocidad de Polanyi, se refiere principalmente al tipo de intercambio que se produce entre personas socialmente iguales y que mantienen relaciones de proximidad. Desde esta concepción, las formas de reciprocidad son más afines a las relaciones sociales de las sociedades igualitarias, y se inspiran en una concepción solidaria de la vida. Así, cuanto mayor sea la proximidad física y afectiva entre las distintas personas, mayor será la probabilidad de desarrollar actitudes de reciprocidad generalizada, ya que se fundamentan en la confianza entre las personas. Esta forma de intercambio es singular y universal y está influenciada e interpretada por muchos factores como son el carácter de la relación entre las personas y entre los grupos, la naturaleza de los beneficios mutuos, el contexto donde emerge, la atribución de contenido simbólico y su intencionalidad práctica.

Cabría aventurar la presencia de un principio de equilibrio que rige el intercambio de dones y las relaciones sociales que genera. Blau (1982) se ha detenido a examinar las relaciones de equilibrio en estas formas de intercambio social. Si se ha prestado un servicio a alguien, se espera que exprese su gratitud y que corresponda cuando surja la ocasión. Si la prestación de un determinado servicio o favor es correspondido, la acción se volverá a repetir, es decir, actúa como un estímulo para volver a prestar otra vez el servicio o la ayuda. Pero Blau sólo se refiere a los comportamientos que se guían por la racionalidad instrumental o búsqueda de metas, olvidando que existen otras actuaciones que están inspiradas en factores diferentes, que no buscan la recompensa, sino que son una manifestación del compromiso hacia algo o alguien. Blau reconoce que estos comportamientos existen, pero no los distingue de otros, ya que considera que son una forma más de intercambio social y, como tal, tienden a crear una diferencia de estatus y poder. Para él, en todo tipo de intercambio suele producirse desequilibrio, ya que, por regla general, una de las partes obtiene más beneficio que la otra. Incluso afirma que el altruismo se fundamenta en el egoísmo, pues la tendencia a ayudar a otros está frecuentemente motivada por la común aceptación de que hacerlo proporciona recompensas sociales. En línea con el pensamiento de Blau, se llega a la conclusión de que el intercambio social que se origina en la donación, aunque pretende el equilibrio entre la acción de dar y la acción de recibir, tiene como finalidad última la aprobación social. Incluso, en muchas ocasiones, el intercambio social produce desequilibrio y desigualdad, ya que 
al prestar un servicio o dar un regalo a otro, se consigue una posición social ventajosa, es decir, se obtiene mayor poder social. Esta es la interpretación que atribuye Blau a las situaciones en las que personas de más estatus dan o prestan una serie de servicios a cambio de obediencia, respeto y poder.

Por tanto, el don por su naturaleza de intercambio social, crea relaciones bilaterales, ya sea desde la concepción de Mauss, desde la consideración de intercambio recíproco de Polanyi o de la interpretación de equilibrio que realiza Blau. La noción que inspira es compleja, ya que no es ni prestación puramente libre y gratuita, ni producción e intercambio basado en la utilidad. Es un "híbrido", en palabras de Mauss, y su esencia consiste en la capacidad de crear relaciones sociales, que no terminan con la donación ni con la restitución, sino en el establecimiento de una espiral de vínculos.

Pero interpretar la teoría del don tan sólo desde el concepto de intercambio, a pesar de su indudable atractivo de concepto-frontera compartido por otras ciencias sociales, sería cercenar las posibilidades explicativas que brinda su identificación como hecho social total, que es como considera Mauss al intercambio de dones. ¿Cómo definir el hecho social total? Del texto se desprende que la noción del hecho social total radica en su capacidad de establecer vínculos de significado social. Es decir, la acción que supone el intercambio de dones puede ser referida al conjunto de significados que atribuyen los hombres en sociedad y que remiten a una totalidad capaz de ser abstraída y convertirse a su vez en vehículo de comunicación.

El don afecta a todos los ámbitos e incluye todos los estatus sociales, lo que le confiere un doble carácter: político y doméstico. Además, establece una regla de conducta general que es obligatoria y, por tanto, tiene carácter jurídico. Igualmente, entra en la esfera del intercambio simbólico que remite a un sistema cultural de signos. Asimismo, forma parte del ritual que representa lo trascendente y, como tal, pertenece al ámbito religioso. También los intercambios tienen un componente social, ya que simbolizan y demuestran que se mantienen las relaciones de estatus, es decir, el don actúa o es mediador del poder social, o lo que es lo mismo, expresa la jerarquía de la sociedad; y, finalmente, tienen un componente económico al incluirse la idea de valor en el proceso de emulación, que está presente en el intercambio de dones. La donación resulta, así, un hecho social total que tiene capacidad de referir al sistema social y de unir la persona al grupo. También tiene la posibilidad de integrar los grupos al establecer referencias compartidas sobre las diferencias existentes, ya que el sentimiento de la integración se sitúa por encima del intercambio material presente en la donación. El intercambio, así considerado, es un vehículo de comunicación social.

Las posibilidades explicativas que brinda la noción de hecho social total, se ven complementadas por su capacidad metodológica ${ }^{3}$, concebida por los coetáneos de Mauss en términos de relación estructural, susceptible de ser convertida en 
modelo que permite combinar sus términos a partir de la plural manifestación de los tipos de intercambio entre individuos y entre grupos, pero especialmente basada en el modelo de los intercambios lingüísticos, origen de una potente tradición investigadora, la sociolingüística, que en el campo de las ciencias sociales llega hasta nuestros días. Desde esta perspectiva, cabría considerar el intercambio social de la donación como un metalenguaje que otorga sentido, con los atributos de permanencia y universalidad, a los diversos códigos de significados que se relacionan en la acción de intercambio. El sentido procede de la intencionalidad integradora, garantía de supervivencia en la condición humana, y se resuelve en el proceso de reconocimiento compartido de este sistema global de comunicación.

De este modo, la aplicación metodológica de la noción del don como hecho social total, permite explicar la evolución histórica que ofrece este tipo de intercambio social desde las sociedades simples a las sociedades complejas, así como las formas en las que se manifiesta en la actualidad. Y aún más importante, posibilita, una vez identificados sus elementos expresivos, conocer en sociedades concretas su entidad y alcance a través de sus dimensiones cuantitativas y cualitativas. En resumen, supone disponer de un poderoso instrumento de análisis para explicar el entramado de relaciones sociales basadas en el intercambio generado por la donación, así como sus manifestaciones en el pasado y en el presente.

\section{VIGENCIA EXPLICATIVA DE LA NOCIÓN DEL DON}

En la moderna sociedad occidental dos transformaciones históricas de gran alcance han afectado al carácter original del don. La primera es la que deriva de la universalidad de los principios de la Ilustración, que suponen la afirmación de la individualidad frente a la colectividad en las relaciones sociales. La segunda es consecuencia de la extensión de la producción industrial y del predominio del carácter mercantil en las formas de intercambio social. Estos dos grandes

\footnotetext{
${ }^{3}$ Rodríguez Zúñiga (1984) en el capítulo de "Teorías del intercambio", señala la interpretación metodológica que realiza Lévi-Strauss al concebir el intercambio en términos estructurales, resolviendo, de este modo, las relaciones entre el plano individual y el social, y entre el plano físico y el psíquico. Para apoyar su interpretación cita un párrafo de la Introducción de Lévi-Strauss a la obra de Mauss: " al final de una serie de reducciones se estará en posesión del hecho social total, que comprenderá: 1) diferentes modalidades de lo social (jurídico, económico, estético, religiosos...); 2) diferentes momentos de una historial individual (nacimiento, infancia, adolescencia, madurez...); 3) diferentes formas de expresión desde fenómenos fisiológicos hasta categorías inconscientes y representaciones conscientes individuales y colectivas. Todo ello es sin duda social, ya que, sólo como hechos de naturaleza social, elementos de tan diversa naturaleza pueden adquirir una significación global y devenir una totalidad".
} 
cambios sociales se han interpretado desde dos construcciones explicativas. De una parte, un modelo de intervención del poder público que hace recaer en el Estado la capacidad para establecer un marco regulador que garantice el entramado de relaciones desde un plano de igualdad entre todos los ciudadanos. De otra parte, un modelo de regulación del mercado basado en el supuesto de concurrencia perfecta, que facilita el intercambio de bienes logrando el beneficio de todos. Ambas explicaciones se han desarrollado en el contexto de concepciones ideológicas diferenciadas, pero comparten un planteamiento común: la singularidad del individuo como sujeto social, que tiene capacidad para elegir racionalmente la adquisición de bienes y decidir la mejor forma de gobierno entre varias alternativas posibles.

Se ha impuesto un prototipo de hombre moderno que afirma su singularidad como sujeto de derechos y consumidor de bienes. La consecuencia ha sido la transformación progresiva del sistema de relaciones sociales y el desplazamiento del intercambio, concebido como hecho social total, del grupo al individuo. ¿Es factible deducir que en este escenario la noción del don, con sus atributos de reciprocidad y vínculos en el marco de un código plural de significados colectivamente compartidos, haya sido superada por el utilitarismo del mercado o por el afán redistributivo del Estado?

La irrupción del mercado que acompaña al desarrollo industrial consagra el principio del crecimiento económico y establece el predominio de un tipo de intercambio basado en el cálculo monetario, liberando a los miembros de la sociedad de toda obligación ligada a las relaciones sociales, en la idea de que toda vinculación obligatoria puede ser remplazada por un bien material. Como subraya Jacques Godbout, "mientras que el don instaura y alimenta una relación social, el mercado aparentemente libera desligándonos de los vínculos que nacen del intercambio, es decir, su libertad consiste en liberarnos de la misma relación social...". En la lógica utilitarista el don se considera una pérdida, una acción inútil, salvo que se le asigne una aplicación de valor con la intención de retorno, desapareciendo la mutua gratificación de la donación, que afecta tanto al que la da, como al que la recibe. Cuando se practica el don se hace desde la lógica del beneficio, es decir, el donante invierte en algo - ayudar a otro- con la intención de obtener ganancias en el futuro y esta inversión debe hacerse con el menor gasto posible para obtener ventaja en el retorno. De este modo, la donación se incluye en la maximización de beneficios (el ejemplo más significativo en la actualidad es la práctica del regalo a los clientes especiales por parte de las empresas). Además, el tipo de intercambio que se produce en el mercado utiliza una referencia común para facilitar el cálculo de la equivalencia. Esta referencia común es el dinero, que permite asignar precios a los actos de intercambio, al tiempo que le resta su capacidad de crear vínculos ${ }^{4}$. Así, frente a la pluralidad de significados afin al intercambio inspirado en la noción del don, se intenta establecer un modelo unívoco. Cuando Simmel (1977) exa- 
RIS

REVISTA INTERNACIONAL DE SOCIOLOCÍA

№ 35 , Mayo-Agosto, 2003

ISABEL DE LA TORRE

mina la creación de valor que origina la utilización del referente monetario en la transacción mercantil, destaca como elemento esencial su capacidad de igualar las acciones de intercambio, ya que la característica de la expresión monetaria es que no posee más cualidades que su cantidad ${ }^{5}$. De este modo, el mecanismo de los precios libera a la circulación de bienes de las vinculaciones personales y establece nuevos códigos de significados basados en la referencia simbólica atribuida a las cualidades de los objetos y concretada en la ordenación de precios. El contexto del mercado es el mundo de los objetos convertibles en referencia monetaria, y cuando el bien que circula en el mercado no es un objeto, sino un servicio, su conversión mercantil se produce a través de la valoración monetaria del tiempo que supone su realización, y sólo si es posible su conversión a una unidad de medida monetaria, figurará en el contexto de referencia del mercado, que invade todos los ámbitos de la vida social. La fuerza del mercado ha llegado a construir una entidad cultural propia, que no sólo vincula las relaciones de intercambio económico con la circulación de bienes y servicios entre individuos y grupos sociales, estableciendo su identificación en la estructura social, sino que su referente simbólico ha llegado a convertir sus signos expresivos en iconos de validez universal.

A pesar de la capacidad transformadora del mercado, en la sociedad actual han persistido formas de intercambio social que escapan a la asignación de precios y cuya existencia sólo puede ser explicada en el contexto de las relaciones sociales que establece la donación y los comportamientos que le son afines, basados en la mutua ayuda, el beneficio compartido, la solidaridad y la orientación al interés general ${ }^{6}$. Estos comportamientos para intervenir en el espacio público se agrupan en un conjunto de entidades y organizaciones que responden a la funcionalidad singular que se les asigna, pero reproducen en esencia un tipo de intercambio plural que se diferencia claramente del intercambio "racional" del mercado. La identificación específica de estas entidades y organizaciones se apoya en varias denominaciones: Tercer Sector, Sector no lucrativo, Economía Social. Pero todas ellas responden al objetivo de reconocer la existencia de actuaciones de intercambio realizadas por sujetos sociales, que no pueden ser explicadas desde el

\footnotetext{
${ }^{4}$ Aquellas culturas, sin embargo, que han seguido conservando la costumbre del trato en el intercambio comercial mantienen esa capacidad social de generar relaciones y vínculos alrededor del acto de compraventa.

${ }^{5}$ Simmel considera la extensión de la referencia monetaria en las formas de intercambio "El mero hecho de que el objeto sea un precio y cueste un precio establece una línea divisoria y, dentro de su cantidad subjetiva de valor, determina la parte con la que participa en la circulación" (pág. 66).

${ }^{6}$ Un ejemplo ilustrativo de una práctica, actual y creciente, del don en las sociedades occidentales es la donación de órganos vitales a personas cuya supervivencia depende directamente de estas donaciones.
} 
utilitarismo del mercado ni, como se expone a continuación, desde la equidad redistributiva del Estado.

El modelo de Estado benefactor que se ha ido instaurando en las sociedades occidentales tras el primer tercio del siglo veinte, ha generalizado la idea de que la solidaridad, la donación y el altruismo son patrimonios casi exclusivos del Estado, ya que muchas de las funciones de asistencia social que se realizaban a través de las redes informales de ayuda mutua, en ocasiones con medios escasos, fueron asumidas progresivamente por el Estado, adquiriendo un fuerte carácter asistencial. Pero, ¿por qué el Estado asume esta responsabilidad? Una de las razones puede hallarse en la misma esencia del don descrita por Mauss: La forma de intercambio que acompaña al don se realiza a priori en forma de donación "voluntaria", pero en realidad son donativos que establecen "obligaciones" basadas en la referencia de reciprocidad del grupo social, que crea entre las partes una serie de relaciones o vínculos, que están por encima de los propios individuos. Son relaciones de carácter triádico, pues no sólo está la relación "ego-alter" y viceversa, sino que hay dependencia con relación al modelo social de intercambio establecido. De algún modo se asemeja a la relación "circular", que define Simmel, cuando describe la relación entre dos individuos, en la que se produce un efecto de reciprocidad derivado del hecho mismo de la interacción ${ }^{7}$. Este elemento social de la donación es el que asume el Estado, al establecer un modelo de redistribución basado en la equidad, modificando el espíritu del don y sustituyendo los vínculos de reciprocidad por relaciones de neutralidad. El Estado intenta institucionalizar el don estableciendo un contrato, que es impuesto a los ciudadanos en regímenes autoritarios y es aceptado por los ciudadanos en las politeyas democráticas.

El contrato garantiza la distribución equitativa de unos bienes, productos y servicios, basada en una pretendida capacidad de elección entre los usuarios. Godbout (1992) argumenta en contra de esta apropiación, ya que el acto espontáneo y gratuito - característica esencial del don - desaparece, y se transforma en una relación de intercambio que se inserta en el modelo de administración burocrática. Además, la lógica del Estado es contraria a la del don porque se fundamenta en la garantía y en la seguridad. No se trata de ofrecer un bien o un servicio que ha de ser devuelto, ni de establecer o de reforzar vínculos entre personas y grupos, sino exigir un derecho que es de todos y que el Estado administra. En este modelo se sustituye el espíritu del don por el de la equidad, tratando a todos por igual.

\footnotetext{
${ }^{7}$ Manuel Herrera describe el estar en relación, obrando uno por referencia al otro, como "una conexión sui generis que en parte depende de ego, en parte de alter, y en parte de una realidad (efectiva o virtual) que no depende de los dos, sino que los excede..", (Herrera, 2000).
} 
RIS

REVISTA INTERNACIONAL DE SOCIOLOGIA

№ 35, May0-Agosto, 2003

ISABEL DE LA TORRE

Pero el debate sobre la crisis del Estado del Bienestar de las últimas décadas ha debilitado los principios en los que se sustentaba y ha obligado a buscar soluciones alternativas para satisfacer los nuevos riesgos y necesidades sociales que la actual configuración estatal no puede cubrir. Las alternativas que en la actualidad se defienden al respecto oscilan entre las tesis neoliberales que buscan un desmantelamiento del Estado de Bienestar o las tesis intervencionistas, que continúan defendiendo el protagonismo del Estado para paliar problemas como la desigualdad y la pobreza. Existe un tercer planteamiento que intenta acercar los dos extremos, para así hacer frente a un problema de organización y protección característico de la nueva sociedad posindustrial, y se opta por una redefinición de la intervención estatal, incluyendo una reactivación de la economía, una revitalización de la sociedad civil con una mayor presencia en las responsabilidades públicas.

En definitiva, tanto el utilitarismo del mercado como el afán redistributivo del Estado han restado espacio y protagonismo al don y al sistema de vínculos que crea. El mercado, reduciendo la compleja naturaleza social del intercambio al cálculo de base monetaria, y el Estado, al constituirse en intermediador exclusivo y desplazar el delicado mecanismo de redistribución que, con anterioridad, venían realizando los cuerpos intermedios de la sociedad ${ }^{8}$.

A pesar de la invasión del Estado y del mercado en el tejido social y sus efectos en las relaciones de intercambio, la capacidad de relación de los sujetos sociales, referida a individuos o a grupos y explicada desde la noción del don, ha persistido en el espacio privado y en el ámbito público. Es el fundamento de los dos tipos de solidaridad, mutualista y altruista, presentes en la sociedad moderna, que identifican a la economía social y al sector no lucrativo, como integrantes del Tercer sector. Cabe incluso afirmar que, a tenor de las investigaciones empíricas más recientes (Salomón y Aneheier, 2001), el Tercer Sector muestra un desarrollo mayor del esperado, pues en la casi totalidad de los países occidentales se asiste a la ampliación de su espacio de influencia y al creciente reconocimiento de las actuaciones que les son propias y de las que les son afines, en el amplio marco de la sociedad civil.

¿Cuál es la razón que explica el reciente protagonismo del Tercer Sector? Una relación de circunstancias puede explicar su expansión y desarrollo. Entre ellas destaca la reacción social contra la universalidad de un mercado global que genera importantes desequilibrios en la evolución prevista del orden económico, político y social, al tiempo que interviene para encontrar las vías que permitan extender los beneficios derivados de la abundancia y de la circulación de bienes. Por otra parte, la constatación por la ciudadanía de los límites a las soberanías

\footnotetext{
${ }^{8}$ Como afirma Iglesias (1986), "la abolición de las fronteras entre sociedad y Estado ha podido conducir a una homogeneización social (distinta de la igualdad), y, paradójicamente, a una politzación universal..."(pág.61).
} 
nacionales y el sentimiento de desconfianza hacia la capacidad de las instituciones administrativas para satisfacer las necesidades presentes y futuras de la población, ha supuesto el fortalecimiento de una conciencia cívica, que a través de la opinión pública y de la acción colectiva, interviene de forma activa y plural en el ejercicio de la igualdad de derechos con carácter universal.

\section{COMPORTAMIENTOS PROSOCIALES Y REDES DE ACCIÓN SOCIAL}

Los elementos expresivos del sistema de comunicación que se explica desde la noción del don, son las modalidades de conducta que se agrupan en las Ciencias Sociales en la categoría de los comportamientos prosociales. En ellos figuran acciones de mutua ayuda, de altruismo, de solidaridad, de colaboración, compasión, condescendencia, disposición no agresiva, división de bienes, empatía, interés por los otros y todas las formas de participación y de actividad tendentes a mejorar el bienestar general según analiza Salfi (1991).

La característica común de todos los comportamientos prosociales es su pertenencia a un sistema de reciprocidad, bien sea intenso y próximo, bien sea extenso en el espacio y en el tiempo, así como su contribución a la cohesión social, al reforzar el sistema de interrelaciones que, de manera opuesta al mercado y al Estado, no se guía por principios de equivalencia y de equidad, sino en la libertad del acto de donación, en el que el sentimiento de pérdida se compensa con la satisfacción de compartir los bienes, consolidar las relaciones personales y favorecer el bienestar general. Aunque un mismo término agrupa este tipo de comportamientos, cabe diferenciar una amplia escala situada entre dos extremos: desde el altruismo, hasta la mutua ayuda con fines económicos.

Los comportamientos más próximos al altruismo y a la solidaridad constituyen el elemento nuclear de los comportamientos prosociales, ya que se basan en la reciprocidad manifiesta y en las donaciones unilaterales basadas en la gratuidad. Pero, ¿cuáles son las razones de orden social que impulsan a los comportamientos prosociales? Algunas de las afirmaciones que hace Mauss sirven para explicar este tipo de conducta, pues lo que se esconde detrás del intercambio, que él describe, es la búsqueda de identidad personal y de reconocimiento social al compartir patrones de comportamiento colectivamente aceptados y ajustados a los valores dominantes, de tal modo que la integración de los individuos en la sociedad se produce a través de estas adscripciones de acciones individuales voluntarias, que son consideradas expresiones de identidad colectiva sustentadas en códigos de significados regidos, en el caso de los comportamientos prosociales, por el altruismo y la solidaridad.

En la exposición de su teoría sobre el reconocimiento social, Honneth (1997) considera que los sujetos sociales requieren más allá de la experiencia 
R I S

REVISTA INTERNACIONAL DE SOCIOLOGIIA

№ 35, May0-Agosto, 2003

ISABEL DE LA TORRE

de dedicación afectiva y de reconocimiento jurídico, una valoración social que les permita compartir un marco de referencia común en el que puedan medirse la significación y la contribución de sus cualidades personales para la vida de los otros. La valoración social, a diferencia del reconocimiento jurídico que expresa la propiedad permanente de los individuos como sujetos de derecho de aplicación universal, remite a un modelo históricamente cambiante, basado en un sistema ordenado de valores cuyo conjunto constituye la evidencia cultural de una sociedad. Conforme las sociedades han ido desdibujando su estructura estamental en el proceso de modernización y, consecuentemente, ha ido perdiendo importancia el grado de consideración social que cada persona podía alcanzar si cumplía las expectativas colectivas vinculadas a su estamento, se han impuesto unas pautas de reconocimiento individual, que refieren a un patrón de valoración común, fruto de la pugna entre los grupos sociales por imponer su escala de valoración social vinculada a su modo de vida. Desde la teoría del reconocimiento, el comportamiento prosocial cumple una doble función: a) como patrón de referencia de un grupo, y b), como forma de identificación personal para integrarse en el grupo, ya que los comportamientos prosociales se interpretan como una forma de interacción en la que los sujetos participan recíprocamente de sus vidas singulares, porque se valoran entre sí de forma simétrica ${ }^{9}$. La valoración simétrica significa la consideración recíproca de la existencia y de las actuaciones de cada uno de nosotros orientada a conseguir objetivos comunes para el conjunto. De este modo, no sólo se produce una tolerancia mutua de carácter pasivo, sino que se establece una participación activa complementaria, ya que, en la medida que cada sujeto se preocupa activamente de actuar en beneficio de otros, contribuye a realizar los objetivos comunes con los que se identifica. A través de la valoración simétrica y de la participación solidaria, cada individuo tiene la oportunidad de sentirse valioso para la sociedad. Ahora bien, este tipo de relación social, basada en el mutuo reconocimiento, presupone un orden moral en el que no se produzcan experiencias de negación y menosprecio ${ }^{10}$. Cuando la solidaridad no se basa en una valoración simétrica, las actuaciones solidarias pueden ser interpretadas como acciones legitimadoras de desigualdades sociales y expresiones de poder, ya que aceptan y mantienen las situaciones de desequilibrio, ante las que sólo cabe el sometimiento o la movilización organizada. Lo que significa que cierta clase de comportamientos prosociales puede ser considerada como un medio para mantener las estructuras sociales de dominación y subordinación y también que,

\footnotetext{
${ }^{9} \mathrm{El}$ mecanismo de las valoraciones simétricas explica por qué en situaciones de guerra se establecen relaciones espontáneas de intercambio solidario superando las fronteras políticas.

${ }^{10}$ Honneth, en la obra citada, analiza cómo en la experiencia negativa del menosprecio, que en sus manifestaciones más visibles afectan a la integridad fisica de las personas (violación), a la integridad social (desposesión y exclusión) y a la valoración social (desprestigio y deshonra), se encuentra el origen de las resistencias y de los conflictos sociales individuales y colectivos.
} 
en el ámbito de la apreciación social, sean mejor valoradas algunas modalidades de comportamiento prosocial frente a otras, como, por ejemplo, el altruismo y la solidaridad.

El altruismo, que Eisenber (1982) define como "comportamientos intencionales y voluntarios cuyo objetivo es el bienestar de los otros, sin la presencia de intereses personales o proyectos de recompensa", requiere de una referencia explicativa complementaria. Aparentemente, las conductas altruistas no son recíprocas, ni se inscriben en un sistema cruzado de interrelaciones. Son intercambios que se producen de forma unilateral y gratuita. El sujeto con este tipo de acción busca el beneficio de otro $u$ otros sin solicitar nada a cambio.¿Por qué se producen los comportamientos altruistas? Son muchas las motivaciones que llevan a los individuos a tener conductas altruistas y todas sus manifestaciones responden, en apariencia, a una misma forma de expresión unilateral y gratuita, pero su explicación social remite a un sistema de intercambio ampliado en el espácio y dilatado en el tiempo. Las explicaciones que aportan algunos autores apuntan en esta dirección.

Godbout (1992) describe la donación altruista como respuesta a un estado de deuda permanente en el que el donante se sitúa y al que se ve obligado a responder de forma incondicional.

Lévi-Strauss (1967) distingue entre el intercambio directo, restringido y binario, que se basa en la reciprocidad, y el intercambio indirecto y generalizado con efectos expansivos en el conjunto social. Los casos más representativos son los de aquellas personas que realizan acciones filantrópicas o altruistas porque se consideran obligadas a devolver los muchos favores que la vida les ha dado.

Por su parte Elster (1985) considera que las acciones altruistas proporcionan a los sujetos seguridad mutua y posibilidad de predecir la actuación recíproca con relación a los intereses colectivos, ya que actúan como factor de orden interno al desarrollar unos principios de integración de las identidades singulares en una colectividad común.

De todos los comportamientos prosociales mencionados, la solidaridad es el que mayor difusión y aceptación tiene en las sociedades modernas. Las definiciones suelen aludir a términos como beneficencia, compartir ideas, equidad y justicia, elementos que sólo explican una parte de la solidaridad. El sociólogo que primero utilizó el término de solidaridad para identificar la relación entre el individuo y la sociedad fue Durkheim, que definió la solidaridad como un conjunto de actitudes y comportamientos que aseguran la cohesión social y la continuidad de la acción colectiva ${ }^{11}$. La utilización actual del término solidari-

\footnotetext{
" En el Prefacio de la primera edición de su obra: La división del trabajo social, se pregunta Durkheim (1987), “¿Cómo es posible que, al mismo tiempo que se hace más autónomo, dependa
} 
dad se reduce a definir los principios en los que se basan los comportamientos o acciones dirigidos a la aceptación común de compartir recursos (con políticas sociales de redistribución) y de asumir riesgos (con actuaciones de movilización social o acciones personales de compromiso). Tanto el comportamiento solidario como el comportamiento altruista, y su interpretación a lo largo del tiempo, pueden explicarse desde unas actitudes personales, que se encuentran influidas por la ordenación de valores vigentes en una sociedad concreta y se materializan en unas pautas de socialización, que requieren de un aprendizaje. Su práctica se inicia en los grupos primarios basados en los lazos de parentesco, de amistad y de vecindad, que forman una red primaria de solidaridad en la que su esencia es la base afectiva de los vínculos, el carácter espontáneo de sus manifestaciones y la débil presencia de estructuras organizativas.

Al ampliarse la dimensión de la sociedad, los comportamientos proseciales se han extendido a otros ámbitos sociales situados fuera del círculo inmediato y próximo de la red primaria de solidaridad. Sus manifestaciones están presentes en la vida laboral, en la vida vecinal y en otros muchos ámbitos de la vida cotidiana. Frente a las manifestaciones de solidaridad primaria, estas expresiones de comportamiento prosocial suelen integrarse en las denominadas redes de acción social y/o solidaridad organizada, que se caracterizan por compartir las afinidadades, la comunidad de intereses y la participación de fines.

El concepto de red social hace referencia a la pluralidad de interrelaciones que se establecen entre los individuos de un conjunto de población con determinados fines ${ }^{12}$. Se trata de relaciones que vinculan a las personas y a los grupos al establecer un objetivo compartido en un contexto temporal de permanencia. Las posibilidades de conexión virtual, que facilita la tecnología informática, han ampliado la difusión de la información y la extensión de nuevas formas de sociabilidad a partir de la noción de estructuras flexibles en las que se producen relaciones flexibles. Desde esta consideración, el comportamiento prosocial se explica en el contexto de unas estructuras reticulares, que van construyendo progresivamente los actores sociales desde el nivel más próximo, constituido por las redes primarias, hasta el nivel que representan las redes de solidaridad

\footnotetext{
el individuo más estrechamente de la sociedad? ¿Cómo puede ser a la vez más personal y más solidario?... Nos ha parecido que lo que resuelve esta aparente antinomia es una transformación de la solidaridad social, debida al desenvolvimiento cada vez más considerable de la división del trabajo".

${ }^{12}$ El concepto de red social procede de la antropología británica y se emplea para designar el conjunto de vínculos establecidos entre los miembros de una población. Son clásicas las obras de Bott (1990 [1957]) y Mitchell (1969). En el estudio sobre el funcionamiento de las redes y su importancia en la construcción del tejido social, se ha insistido principalmente en su capacidad para establecer interrelaciones sociales, y en las posibilidades que brinda como herramienta de análisis para explicar la estructura social desde el concepto de vínculo social (Requena, 1991 y 1994).
} 
organizada o redes societarias, que proyectan sus efectos sobre el conjunto de la sociedad ${ }^{13}$ con las que se identifican los sujetos sociales al participar, con su aportación de tiempo y/o de recursos destinados, a causas que son asumidas por organizaciones y entidades a través de una comunidad de fines y una representación simbólica de principios y valores. Y al igual que el modelo de redes basadas en la mutua ayuda permite explicar la existencia de cooperativas y mutualidades, como consecuencia de la reciprocidad de intereses orientados a compartir un beneficio común, la estructura de redes de acción colectiva explica la existencia de formas organizadas de los comportamientos prosociales orientados a resolver situaciones de desigualdad en la disponibilidad de recursos y la atención a fines de interés colectivo, como es el caso de las asociaciones y fundaciones.

Las posibilidades que actualmente brindan las conexiones informáticas para la creación de redes han ampliado la difusión de los mensajes y la capacidad de movilización, de tal modo que las causas que dan origen a la solidaridad pueden estar situadas geográficamente lejos de quienes ofrecen respuestas activas, y en ocasiones, estas causas lejanas generan mayor grado de participación de los ciudadanos que las causas más cercanas. Se ha argumentado sobre el riesgo de una manipulación de la implicación, personal y colectiva, que se realiza por este medio (los denominados agujeros de la red: Castells, 2001); pero el debate más acentuado en la actualidad es el de la utilización que se hace de la solidaridad desde situaciones de desigualdad económica y social, como parte de un espectáculo guiado por los medios de comunicación, perdiendo así su significado original, trivializando la realidad y movilizando comportamientos solidarios $a$ distancia. A los riesgos mencionados cabe añadir que este tipo de solidaridad virtual ha debilitado la fortaleza de los vínculos y ha diluido el grado de implicación personal. Pero, desde una perspectiva metodológica, ha reforzado el concepto de red global, ya que el término red social ha pasado de tener un significado sociométrico (Beltrán, 1989) ${ }^{14}$, aplicable a grupos pequeños, a convertirse en un procedimiento de identificación de los vínculos sociales existentes en conjuntos de población abiertos, que pueden ser considerados como manifestaciones de una red global, que actúa como una estructura fluida de relaciones, que ha incrementado su protagonismo público ejercitando la virtud cívica basada en el principio de la confianza generalizada (Herreros, 2002). La consideración amplia del concepto de red permite interpretar el concepto de participación social en las entidades que integran el Tercer Sector como un ejercicio de ciudadanía, asimilada a la

\footnotetext{
${ }^{13}$ Salvador Giner califica de transcendencia secular a esta proyección de la conducta altruista más allá de la comunidad de pertenencia.

${ }^{14}$ Beltrán (1989) explica la evolución experimentada por las técnicas iniciadas por J. Moreno en grupos pequeños hasta convertirse en instrumento cualitativo para el estudio de las relaciones interpersonales en conjuntos abiertos estructurados como redes.
} 
integración social, y también como una forma de pertenencia a una red global, asimilada al concepto de sociedad civil organizada, que ofrece nuevas formas de identidad colectiva frente al Estado y al mercado.

\section{LA SOCIEDAD CIVIL ORGANIZADA}

El conjunto de redes de solidaridad y de acción social suele identificarse con el término de sociedad civil. El concepto de sociedad civil ofrece varios significados, aunque básicamente se pueden resumir en dos. En primer lugar, destacan las interpretaciones que hacen referencia a las instituciones intermediarias entre el individuo, por un lado, y el Estado y el mercado, por otro. Conceden a la sociedad civil la capacidad de construir estructuras de solidaridad a través de instituciones y entidades que no deben ser colonizadas ni por el Estado ni por el mercado, es decir, deben ser y permanecer autónomas, ofreciendo un soporte ético a la sociedad. En segundo lugar, están las interpretaciones que opinan que la sociedad civil está ligada al sistema legal moderno, al ejercicio de una ciudadanía que defiende intereses colectivos en espacios públicos. Para los defensores de esta perspectiva, la sociedad civil tiene la función de reclamar la atención de cualquier forma de poder que opera en espacios públicos, para resolver demandas insatisfechas o anticipar la protección de nuevas necesidades de grupos sociales. Es decir, colabora activamente en la "visibilidad" de actividades sociales que requieren reconocimiento institucional.

Tanto la primera como la segunda interpretación aluden a la existencia de estructuras organizadas que posibilitan la acción y la intervención. Desde la perspectiva individualista, puede decirse que la sociedad civil se vincula al hombre autónomo que consigue conquistar por sí mismo la prosperidad económica y los derechos civiles que le protegen del poder político, y le habilitan para intervenir activamente en la vida social y en los espacios públicos. Así, por ejemplo, para Giddens (1997), cuando las personas no se sienten partícipes en la configuración de su personalidad buscan en otras esferas nuevos lugares de encuentro, como son los movimientos sociales y las organizaciones del Tercer Sector, espacios de seguridad individual y solidaridad con los demás. Este cambio de actitud de los sujetos puede ser interpretado como una reivindicación de la ciudadanía exigiendo recuperar su papel dentro de los amenazados mundos de la vida cotidiana.

Por su parte, Pérez Díaz (2003) establece que el término de "sociedad civil" ha sido usado como sinónimo de sociedad política y como oposición al Estado. Igualmente, cree que el concepto puede ser utilizado en sentido amplio, es decir, como entramado de instituciones sociopolíticas que incluyen un gobierno limitado al operar bajo el imperio de la ley. La sociedad civil, en este sentido, está formada por un conjunto de instituciones basadas en acuerdos voluntarios entre agentes autónomos, y una esfera pública en la que los agentes debaten entre sí y 
con el Estado acerca de los asuntos públicos. Por otro lado, el concepto puede ser utilizado de manera más restrictiva, refiriéndose sólo a las instituciones sociales, tales como el mercado y asociaciones, y a la esfera pública, excluyendo así a las instituciones estatales ${ }^{15}$. En ambos enfoques, la sociedad civil se basa en el principio de universalidad compartida, frente al principio de territorialidad del poder político y el principio de utilización de recursos del poder económico. A la sociedad civil se le asigna una función de equilibrio frente al Estado y al mercado. Su presencia es posible en la medida en que los actores sociales tienen voz propia, sintiéndose protagonistas de un espacio social autónomo que disputa o comparte la capacidad de intervención en la esfera pública. La sociedad civil se configura como el espacio donde converge lo público y lo privado, el lugar donde prima el bien público y la búsqueda del beneficio para la comunidad. Así como la sociedad civil necesita del doble espejo del mercado y del Estado para delimitar su "espacio privado-público", como acertadamente es denominado por Giner y Sarasa (1997), y depende también del sector público y del sector privado para disponer de recursos y consolidar su estructura organizativa, así también, los actuales modelos de mercado y de Estado necesitan de la presencia reconocida de la sociedad civil, debido, por una parte, a la disgregación de la segmentación social, la concentración de los mercados y el consiguiente aumento de los riesgos sociales, y por otra parte, a la saturación del modelo de Estado Social y sus limitaciones para satisfacer la demanda de nuevos derechos sociales ligados a los estilos de vida cotidiana y la creciente internacionalización de los problemas sociales.

La sociedad civil tiene entidad para expresar su opinión y mostrar su oposición tanto a las medidas que adopta el poder político, como a las actuaciones de las empresas transnacionales, ya que el vértice de la sociedad globalizada es ocupado en mayor medida por las grandes empresas multinacionales que por el Estado. $\mathrm{Y}$ en tanto se hace efectivo el reconocimiento a la legitimidad que procede de las instituciones internacionales, la sociedad civil y los nuevos movimientos sociales ${ }^{16}$ ocupan un espacio propio y proponen un tipo de sociedad en la que participa una ciudadanía activa en la esfera pública basada en el

\footnotetext{
${ }^{15}$ Esta doble referencia del concepto de sociedad civil es explicada por Pérez Díaz como consecuencia de la doble tradición intelectual presente en el origen del concepto: la tradición de los filósofos escoceses (Ferguson, Kettler y Forbes) y la tradición de Hegel.

${ }^{16}$ Laraña (1999) considera a los movimientos sociales "portadores de identidades" con capacidad para definir un nuevo concepto de ciudadanía social.

Otros autores, como Castells (1998) o como Tezanos y Villalón (2002), consideran a los movimientos sociales como sujetos "creadores de identidades" con capacidad para formalizar nuevas instituciones sociales.
} 
RIS

BEVISTA INTERNACIONAL DE SOCIOLOGIA

No 35, Mayo-Agosto, 2003

ISABEL DE LA TORRE

principio de responsabilidad universal. El concepto de ciudadanía activa requiere del reconocimiento explícito de la existencia de sujetos y actores sociales que ejercitan derechos y obligaciones, evitando el riesgo de ser absorbidos por los interlocutores tradicionales del espacio público, que son los partidos políticos, o de ser mediatizados en exceso por los agentes sociales que defienden intereses de grupo. La ciudadanía debe ser entendida como práctica efectiva en la esfera pública del conjunto de derechos y deberes de los sujetos sociales, ya sean individuos o actores colectivos, que formalizan su actuación y se organizan en entidades que responden a sus propios fines ${ }^{17}$.

Las entidades del Tercer Sector se vinculan a la comunidad, nacen de la base, de aquella zona social donde los grupos primarios y secundarios se autogestionan y se autorregulan, contribuyendo a la construcción de la vinculación social de los sujetos. En el conjunto de entidades que integran el Tercer Sector, las asociaciones son las organizaciones que constituyen su núcleo central, hasta el punto de dar nombre a la totalidad del Tercer sector, al que se llega a identificar con el término de Sector Voluntario.

\section{CONCLUSIONES}

En este artículo se ha analizado la relación existente entre las organizaciones solidarias y de mutua ayuda y el desarrollo experimentado por la sociedad civil, cuando esta última se rige por el principio de universalidad, y las entidades que integran el Tercer Sector se basan en principios de identificación, proximidad y ayuda mutua? En general, son organizaciones que se caracterizan por tener una cultura propia - altruista, solidaria, cooperativa - , por desarrollar una actuación propia y diferenciada, es decir, por elaborar "formas autónomas de intercambio social" guiadas por su orientación al bienestar general. Además, producen un modo de funcionamiento propio y producen "bienes relacionales" que se caracterizan por "no ser ni estrictamente públicos ni estrictamente privados, de no ser competitivos según juegos de suma cero y sólo pueden ser producidos y consumidos conjuntamente por los participantes en las redes informales - bienes relacionales primarios-y en las redes asociativas - bienes relacionales secundarios-" (Donati, 2000). Son organizaciones cuyos resultados se miden no sólo por los bienes y servicios que ofrecen, sino por su contribución en términos de solidaridad, cohesión social y establecimiento de vínculos en el marco de la confianza generalizada, que es el supuesto básico del ejercicio cívico. En sociedades concretas, la consolidación de la sociedad civil organizada depende del desarrollo y de la

\footnotetext{
${ }^{17}$ Funes (1995) ha destacado la doble dimensión de estas organizaciones que tienen carácter privado y a la vez una proyección pública.
} 
vitalidad alcanzados por el conjunto de entidades que integran el Tercer sector. Cabe preguntarse si, a través de los indicadores de las principales magnitudes de sus entidades (asociaciones, fundaciones, cooperativas y sociedades laborales), es posible conocer la dimensión de la sociedad civil organizada y el alcance de su capacidad de actuación.

La "presencia" de una sociedad civil organizada puede identificarse no sólo por la existencia de actores sociales que intervienen en la esfera pública con capacidad de autorganizarse, sino por el número de entidades asociativas y las funciones que cumplen. Un modo de conocer la "dimensión" de la sociedad civil es obtener información sobre el grado de pertenencia y participación de los sujetos sociales en las redes de solidaridad organizada. Finalmente, comprobar su "vitalidad" requiere conocer el grado de implantación de los valores que se asocian a las características del Tercer Sector. Son los valores de solidaridady cohesión social, responsabilidad social y compromiso, autonomía e independencia, democracia y participación; y su "desarrollo futuro" está relacionado directamente con la proyección de su imagen pública y su capacidad de representación simbólica.

De las argumentaciones precedentes cabe resumir que el Tercer sector en el marco de la sociedad civil organizada, establece un sistema propio de intercambio de bienes relacionales que se orientan al bienestar general, cuya permanencia depende tanto de la dimensión que ocupa en el espacio público, como de la valoración que proyecta su imagen pública en el conjunto de la sociedad y cuya vitalidad es garantía de bienestar colectivo y de equilibrio social.

\section{BIBLIOGRAFÍA}

BAREA, J. y J.L. MONZÓN (dir.) (2002), La economía social en España en el año 2000, Valencia, CIRIEC.

BELTRÁN, M. (1989), "Cinco vías de acceso a la realidad social”, en M. García Ferrando, F. Alvira, y J. Ibañez (coords.), El análisis de la realidad social. Métodos y técnicas de investigación, $2^{\mathrm{a}}$ ed., Madrid, Alianza.

BLAU, P. (1982), Intercambio y poder en la vida social, Barcelona, Hora.

BOOT, E. (1957), Family and Social Network, Londres, Tavistock.

CASTELLS, M. (1998), La era de la información: Economia, sociedad y cultura, vol. 2, El poder de la identidad, Madrid, Alianza.

(2001), La galaxia internet, Barcelona, Areté.

DONATI, P. (1997), "El desarrollo de las organizaciones del Tercer Sector en el proceso de modernización y más allá", Reis, nº 79, pp. 113-141. 
RIS

REVISTA INTERNACIONAL DE SOCIOLOCIA

№ 35, Mayo-Agosto, 2003

(2000), La cittadinanza societaria, Roma, Laterza.

DURKHEIM, E. (1987), La división del Trabajo Social, Madrid, Akal.

EISEMBER, N. (ed.) (1982), The Development of Prosocial Behabior, Nueva York, Academic Press.

ELSTER, J. (1985), “Rationality, morality and collective action”, Ethics, n ${ }^{\circ} 96$.

FUNES RIBAS, M. J. (1995), La ilusión solidaria: las organizaciones altruistas como actores sociales en los regimenes democráticos, UNED, Madrid.

GIDDENS, A. (1999), La tercera via. La renovación de la socialdemocracia, Madrid, Taurus.

GINER, S. (1995), "Lo privado público: altruismo y politeya democrática", Revista de Estudios Politicos, $\mathrm{n}^{\circ}$ 88, Abril-Junio, pp. 9-28.

GINER, S. y S. SARASA (1997), Buen gobierno y politica social, Barcelona, Ariel.

GODBOUT J. T. (1992), L'Esprit du don París, La Découverte.

HERRERA, M. (1998), El tercer sector en los sistemas de bienestar, Valencia, Tirant lo blanch.

(2000), “La relación social como categoría de las ciencias sociales", Reis, n 90, pp. 37-77.

HERREROS, F. (2002), “¿Son las relaciones sociales una fuente de recursos? Una definición del capital social”, Papers, $n^{\circ}$ 67, pp. 129-148.

HONNETH, A. (1997), La lucha por el reconocimiento, Barcelona, Crítica.

IBAÑEZ, J. (1994), El regreso del sujeto, Madrid, Siglo XXI.

IGLESIAS, Mª.C. (1986), Los cuerpos intermedios y la libertad en la sociedad civil, Madrid, INAP.

LARAÑA, E. (1999), La construcción de los movimientos sociales, Madrid, Alianza.

LÉVI-STRAUSS, C. (1967), Les structures eélémentaires de la parenté, París, Mouton.

MAUSS, M. (1991), "Ensayo sobre los dones", Sociologia y Antropologia, Madrid, Tecnos.

MITCHELL, J.C. (1969), Social Networks in Urban Situations, Manchester, Manchester University Press.

PÉREZ DÍAZ, V. (1997), La esfera pública y la sociedad civil, Madrid, Taurus.

(2003), El Tercer Sector Social en España, Madrid, Ministerio de Trabajo y Asuntos Sociales.

POLANYI, K. (1989), La gran transformación: crítica del liberalismo económico, La Piqueta, Madrid. 
RAMOS, R y F. GARCÍA (coords.) (1999), Globalización, riesgo y reflexividad. Tres temas de la teoria social contemporánea, Madrid, CIS.

REQUENA, F. (1991), Redes sociales y mercado de trabajo, Madrid; CIS.

(1994), Amigos y redes sociales, Madrid, CIS.

RODRÍGUEZ CABRERO, G. (Coord.) (2003), Las entidades voluntarias de acción social en España, Madrid, Fundación FOESSA.

RODRÍGUEZ CABRERO, G. y D. SOTELSEK SALEM (2003), Apuntes sobre bienestar social Madrid, Universidad de Alcalá de Henares.

RODRÍGUEZ ZÚNIIGA, L. (1984), "Variaciones sobre la teoría del intercambio", Sociologia contemporánea. Ocho temas a debate, Madrid, CIS.

SALAMÓN, L.M. y H.K. ANEHEIER (2001), La sociedad civil global. Las dimensiones del sector no lucrativo, Bilbao, Fundación BBVA.

SALFI. B.G. (1991), "Possiamo davvero apprendere a star bene con gli altri? La rispota, la prosocialita", Rassegna italiana di Sociologia, a. XXXII, $\mathrm{n}^{\circ} 3$, pp 267-311.

SIMMEL, G. (1977), La filosofia del dinero, Madrid, Instituto de Estudios Políticos.

(1927), "Sociología: estudio sobre las formas de socialización", Revista de Occidente, Madrid.

TEZANOS, J.F. y J.J. VILLALÓN (2002), Estudio DELPHI sobre tendencias económicas, politicas y sociales, Madrid, Sitema. 